Check for updates

Cite this: Chem. Sci., 2019, 10, 8889

๑ All publication charges for this article have been paid for by the Royal Society of Chemistry

Received 20th June 2019

Accepted 2nd August 2019

DOI: $10.1039 / c 9 s c 03052 b$

rsc.li/chemical-science

\title{
Zinc ion interactions in a two-dimensional covalent organic framework based aqueous zinc ion battery $\dagger$
}

\author{
Abdul Khayum M, (D) ab Meena Ghosh, (D) ab Vidyanand Vijayakumar, (D) ab \\ Arjun Halder, (D) ab Maryam Nurhuda, ${ }^{c}$ Sushil Kumar, ${ }^{b}$ Matthew Addicoat, (DD c \\ Sreekumar Kurungot (D) *ab and Rahul Banerjee (D) *d
}

\begin{abstract}
The two-dimensional structural features of covalent organic frameworks (COFs) can promote the electrochemical storage of cations like $\mathrm{H}^{+}, \mathrm{Li}^{+}$, and $\mathrm{Na}^{+}$through both faradaic and non-faradaic processes. However, the electrochemical storage of cations like $\mathrm{Zn}^{2+}$ ion is still unexplored although it bears a promising divalent charge. Herein, for the first time, we have utilized hydroquinone linked $\beta$ ketoenamine COF acting as a $\mathrm{Zn}^{2+}$ anchor in an aqueous rechargeable zinc ion battery. The chargestorage mechanism comprises of an efficient reversible interlayer interaction of $\mathrm{Zn}^{2+}$ ions with the functional moieties in the adjacent layers of COF $\left(-182.0 \mathrm{kcal} \mathrm{mol}^{-1}\right)$. Notably, due to the well-defined nanopores and structural organization, a constructed full cell, displays a discharge capacity as high as $276 \mathrm{~mA} \mathrm{~h} \mathrm{~g}^{-1}$ at a current rate of $125 \mathrm{~mA} \mathrm{~g}^{-1}$.
\end{abstract}

\section{Introduction}

Two-dimensional (2D) porous crystalline covalent organic frameworks (COFs) are integrated from pre-designed symmetric organic building units and self-assembled by $\pi-\pi$ stacking. $^{1}$ Due to the structural tunability, well-defined porosity, and high chemical stability, COFs have been widely explored as electrode materials for electrochemical energy storage. ${ }^{2}$ However, until now, the energy storage applications in COFs were mostly limited to the monovalent ions like $\mathrm{H}^{+}, \mathrm{Li}^{+}$, and $\mathrm{Na}^{+}$that could only carry forward single electron reactions. Although, divalent aqueous zinc ion batteries are observed to be cost-effective and superior in terms of safety and recyclability than the monovalent $\mathrm{Li}^{+}, \mathrm{Na}^{+}$metal-ion batteries, ${ }^{3}$ it is extremely challenging to design an organic polymeric electrode that can act as a $\mathrm{Zn}^{2+}$ acceptor. A few literature reports deal with small molecules as cathode materials for accepting the electrophilic $\mathrm{Zn}^{2+}$ ions through coordination bonds. ${ }^{4}$ However, limited chemical and thermal stabilities of these organic molecules and the undesirable leaching of the active electrode materials during the

\footnotetext{
${ }^{a}$ Academy of Scientific and Innovative Research (AcSIR), Sector 19, Kamla Nehru Nagar, Ghaziabad, Uttar Pradesh-201002, India

${ }^{b}$ Physical and Materials Chemistry Division, CSIR-National Chemical Laboratory, Dr. Homi Bhabha Road, Pune-411008, India. E-mail: k.sreekumar@ncl.res.in

${ }^{c}$ School of Science and Technology, Nottingham Trent University, Clifton Lane, NG11 $8 N S$ Nottingham, UK

${ }^{d}$ Department of Chemical Sciences, Indian Institute of Science Education and Research (IISER), Mohanpur Campus, Mohanpur, Kolkata, 741252 India. E-mail: r.banerjee@ iiserkol.ac.in

$\dagger$ Electronic supplementary information (ESI) available: Experimental section. See DOI: $10.1039 / \mathrm{c} 9 \mathrm{sc} 03052 \mathrm{~b}$
}

electrochemical cycling hampers their performance and creates a need for a polymeric electrode capable of hosting $\mathrm{Zn}^{2+}$ ions. Keeping this in perspective, herein, we have demonstrated hydroquinone based covalent organic framework ${ }^{5}$ (HqTp) acting as an efficient polymeric cathode material for an aqueous zinc ion battery. We anticipated that a COF must be enriched with several nucleophilic centers so that it can anchor to a significant number of divalent $\mathrm{Zn}^{2+}$ ions. Furthermore, the framework must be constructed from such building blocks, which can act as nucleophilic centers for efficient interaction with $\mathrm{Zn}^{2+}$ under electrochemical conditions.

It is well documented that the $\mathrm{C}=\mathrm{O}$ and $\mathrm{N}-\mathrm{H}$ functionalities in polymers are capable of coordinating $\mathrm{Zn}^{2+}$ ions in an electrochemical cell. ${ }^{4,6}$ Both $\mathrm{C}=\mathrm{O} \cdots \mathrm{Zn}$ and $\mathrm{Zn} \cdots \mathrm{N}-\mathrm{H}$ interactions are reversible in nature and can "make and break" during the electrochemical redox process. Thus, an electron-rich backbone in the HqTp facilitates efficient coordination with $\mathrm{Zn}^{2+}$ ions. HqTp exhibits an excellent discharge capacity of $276 \mathrm{~mA} \mathrm{~h} \mathrm{~g}^{-1}$ at a current of $125 \mathrm{~mA} \mathrm{~g}^{-1}$ in an operating potential of 0.2 to $1.6 \mathrm{~V} v$ s. $\mathrm{Zn} / \mathrm{Zn}^{2+}$ due to the efficient intermolecular $\mathrm{O} \cdots \mathrm{Zn}(\sim 2.0$ $\AA)$ and $\mathrm{N} \cdots \mathrm{Zn}(\sim 2.0 \AA)$ interactions. ${ }^{4 a, 7}$ To the best of our knowledge, this is the first report of a COF based aqueous zinc ion battery and puts forward a novel concept based on the zinc ion interaction with a porous crystalline and polymeric organic cathode.

\section{Results and discussion}

The HqTp COF is synthesized by a solid-state mechano-mixing of 2,5-diaminohydroquinone dihydrochloride (Hq) and 1,3,5triformylphloroglucinol (Tp) in the presence of $p$ - 
a)

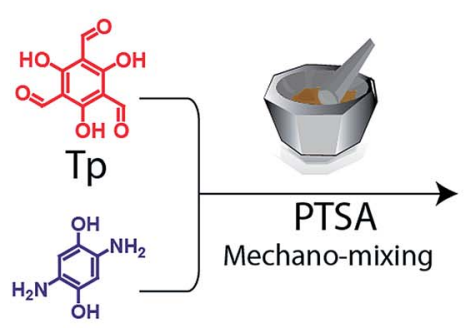

$\mathrm{Hq}$
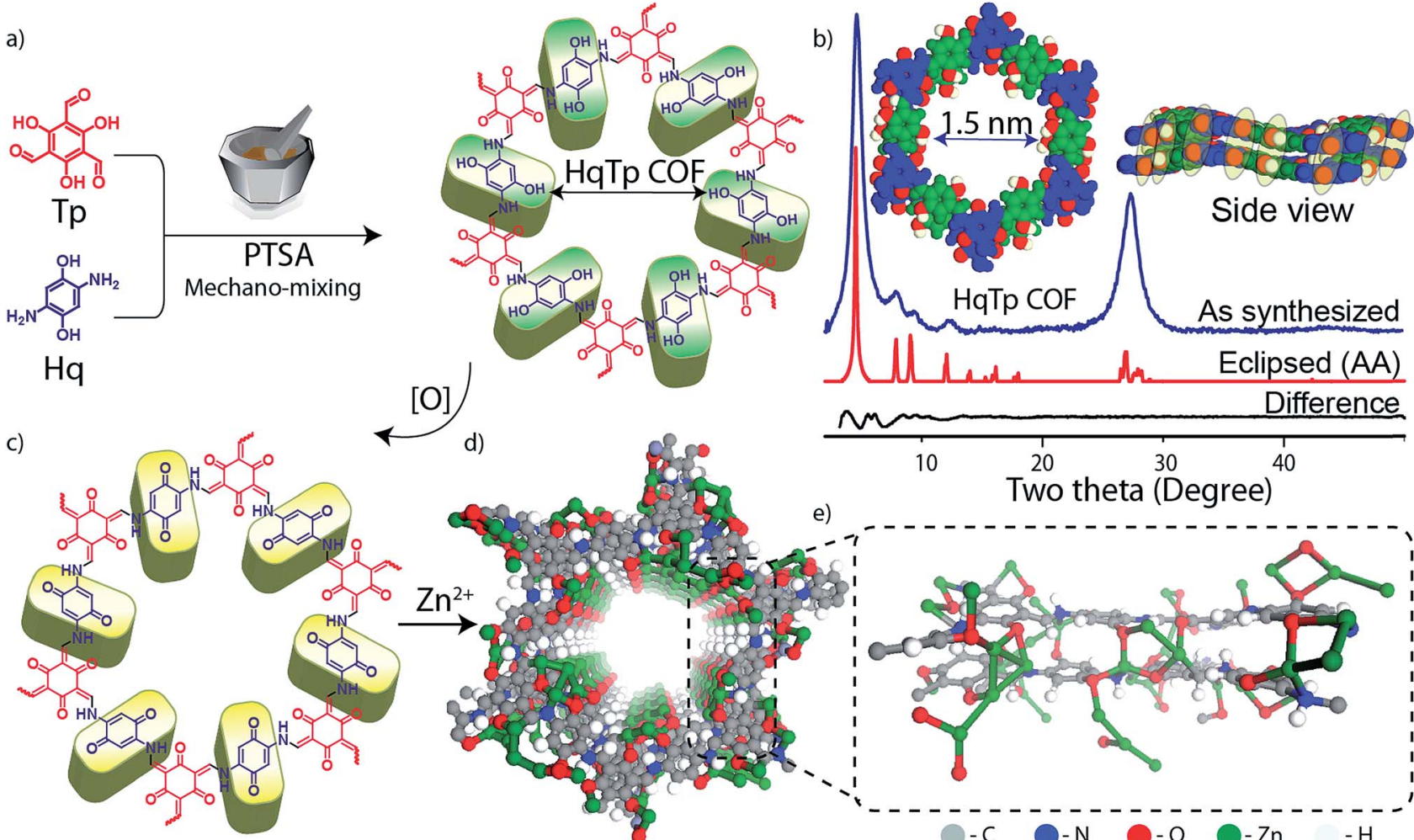

10

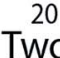

Two theta (Degree)

e)

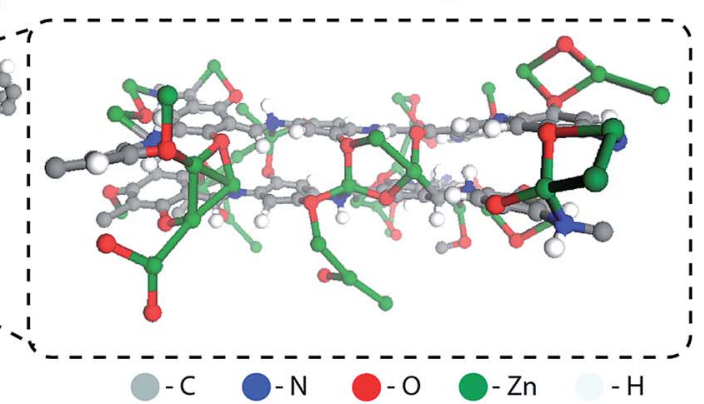

Fig. 1 (a) Schematic representation of the synthesis of HqTp (Hq-2,5-diaminohydroquinone, Tp-1,3,5-triformylphloroglucinol). (b) Powder Xray diffraction pattern with the AA eclipsed slipped SCC-DFT model. (c) The electrochemical oxidation of hydroquinone to quinone in HqTp (d and e). The DFTB model of interlayer interaction of $\mathrm{Zn}^{2+}$ cations with the adjacent layers of HqTp.

toluenesulfonic acid (PTSA $\cdot \mathrm{H}_{2} \mathrm{O}$ ) as a catalyst (Fig. 1a; ESI, S1 $\dagger$ ). A black coloured product was obtained after removing the impurities upon wash with water, $N, N$-dimethylacetamide (DMAc) and acetone. The crystalline framework structure and an ordered integration of the building blocks throughout the network is confirmed by the PXRD characterization. The powder X-ray diffraction (PXRD) profile exhibits sharp peaks at the $2 \theta$ position of $4.6^{\circ}, 8.0^{\circ}, 9.4^{\circ}, 12.4^{\circ}$ and $27.3^{\circ}$ (Fig. 1b). The sharp and intense peaks at 4.6 and $27.3^{\circ}(2 \theta)$ correspond to the reflections from 100 and 001 planes, which indicates the existence of a periodic structure. Moreover, the experimental PXRD pattern matches with the simulated PXRD pattern with a slipped eclipsed orientation as modeled using SCC-DFTB (Fig. 1b; ESI S2 and S3†).

The $\beta$-ketoenamine framework formation is confirmed by the new peaks in FT-IR spectra at 1583, 1551 and $1244 \mathrm{~cm}^{-1}$, which correspond to $\mathrm{C}=\mathrm{O}, \mathrm{C}=\mathrm{C}$ and $\mathrm{C}-\mathrm{N}$ bonds (all generated after enol-keto tautomerization; ESI; Fig. S6†). Additionally, the ${ }^{13} \mathrm{C}$ solid-state CP-MAS NMR shows enamine and $\alpha$-enamine carbon peak resonances at 142 and $105 \mathrm{ppm}$ respectively and similarly $\mathrm{C}=\mathrm{O}$ carbon peak at 184 ppm (Fig. 2c; ESI, Fig. S7 $\dagger$ ). The thermogravimetric analysis (TGA) of HqTp displays thermal stability up to $380{ }^{\circ} \mathrm{C}$ (ESI, Fig. S9 $\dagger$ ). Brunauer-Emmett-Teller (BET) analysis, using $\mathrm{N}_{2}$ adsorption at $77 \mathrm{~K}$ shows a moderate surface area of $113 \mathrm{~m}^{2} \mathrm{~g}^{-1}$ (ESI, Fig. S10 $\dagger$ ). The non-local density functional theorem (NLDFT) provides a sharp pore size distribution around $1.5 \mathrm{~nm}$ (ESI, Fig. S11†).

The presence of $\mathrm{C}=\mathrm{O}$ moieties in HqTp COF are principally responsible for the storage of $\mathrm{Zn}^{2+}$ ions. These are the $\mathrm{C}_{3}$ symmetric $\mathrm{C}=\mathrm{O}$ groups resulting from the enol to keto tautomerism and the $\mathrm{C}_{2}$ symmetric $\mathrm{C}=\mathrm{O}$ group from electrochemically oxidized hydroquinone $\operatorname{linker}^{8}$ (Fig. 1a, c, and 3a; ESI, Fig. S8 $\dagger$ ). The hexagonal $2 \mathrm{D}$ lattice enriched with a large number of $\mathrm{C}=\mathrm{O}$ groups, stacked with an interlayer distance of $3.4 \AA$, can efficiently host a significant amount of $\mathrm{Zn}^{2+}$ in between the two-dimensional layers. Also, the crystalline honeycomb structure of HqTp provides a unique pore size of $1.5 \mathrm{~nm}$, which, we believe, further boosts the lucid movement of $\mathrm{Zn}^{2+}$ ions through the entire organic cathode without any interruptions.

DFTB calculations were used to probe the nature of the interaction of $\mathrm{Zn}^{2+}$ with the COF backbone. They suggest the possibility of the prominent interlayer interactions of $\mathrm{Zn}^{2+}$ ions with nucleophilic centers of COF (Fig. 1e, ESI, Fig. S3 and S4 $\dagger$ ). The $\mathrm{C}=\mathrm{O} \cdots \mathrm{Zn}(2-2.3 \AA)$ and $\mathrm{Zn} \cdots \mathrm{N}-\mathrm{H}$ distances $(\sim 2.0 \AA)$ agree with the possibility of intermolecular interactions. The DFTB models of $\mathrm{AA}$ and slipped $\mathrm{AA}$ COF $\cdots \mathrm{Zn}^{2+}$ interaction show various structural possibilities including a formation of a $\mathrm{Zn}^{2+}$ ion cluster inside the pores. Also, a large enhancement in the per-layer stabilization is observed for the discharged HqTp $\cdots$ $\mathrm{Zn}^{2+}$ adduct $\left(-182.0 \mathrm{kcal} \mathrm{mol}^{-1}\right)$ than the pristine COF 

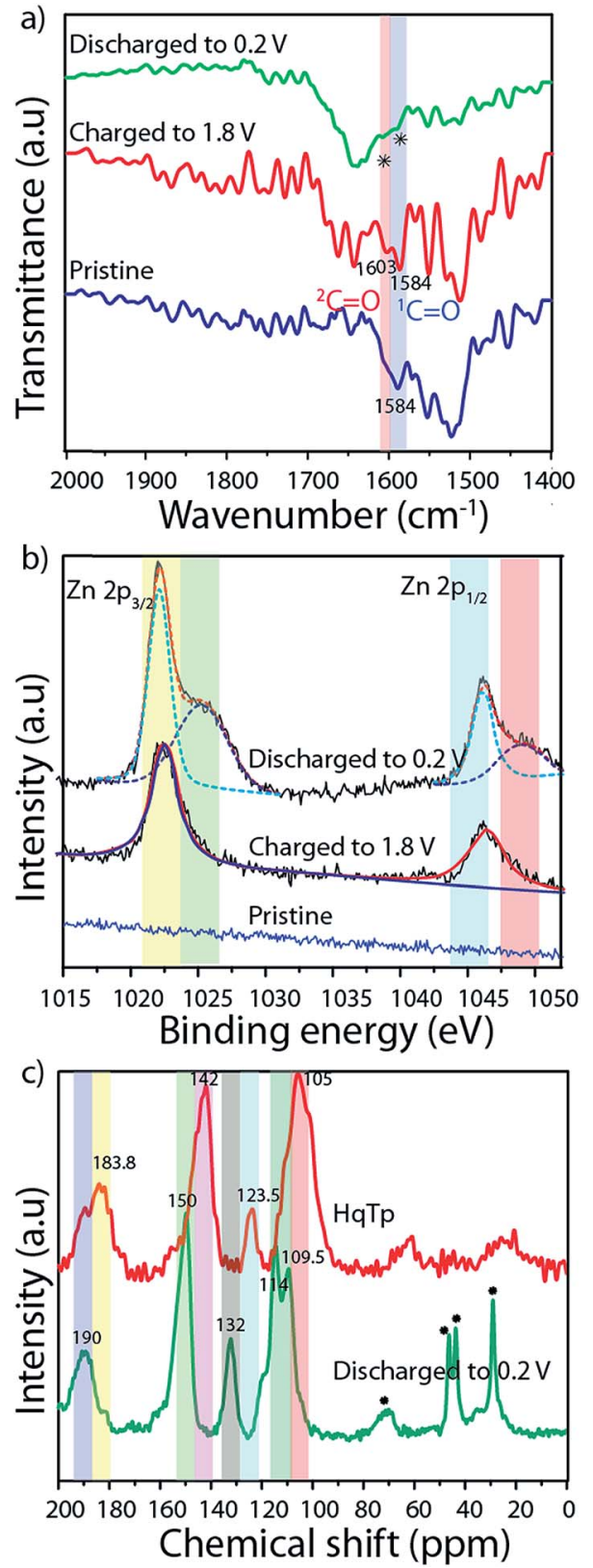

Fig. 2 (a) FT-IR of pristine; charged and discharged cathodes. (b) XPS analysis of pristine; charged and discharged cathodes. (c) ${ }^{13} \mathrm{C}$ CP-MAS NMR of HqTp and the discharged cathode (all the charging and discharge potential are represented vs. $\mathrm{Zn} / \mathrm{Zn}^{2+}$ reference).

$\left(-40.0 \mathrm{kcal} \mathrm{mol}^{-1}\right)$ which indicates favorable $\mathrm{Zn}^{2+}$ ion interaction. To understand the role of electrochemical active sites for $\mathrm{Zn}^{2+}$ anchoring in concerned COF, we have performed and compared the electrostatic potential mapping (ESP) of HqTp with benzene linked analog PaTp COF (ESI, Fig. S5 and S30†). ESP of the unit cell of HqTp displays a potential range from -0.33 au (red) to 0.061 au (blue). Herein, the negative ESP (red) reflects the affinity of the sites toward the $\mathrm{Zn}^{2+}$ uptake. Therefore, from ESP, it is clear that the quinone ' $\mathrm{C}=\mathrm{O}$ ' and $\mathrm{Tp}$ ' $\mathrm{C}=\mathrm{O}$ ' in HqTP exhibits more nucleophilicity compared to the ' $\mathrm{N}-\mathrm{H}$ ' sites. Whereas, the ESP of benzene linked PaTp COF showcases only $\mathrm{Tp}$ ' $\mathrm{C}=\mathrm{O}$ ' groups as active sites for the uptake of $\mathrm{Zn}^{2+}$.

We have analyzed the working electrode (cathode) at three different electrochemical conditions to elucidate the probable mechanism of the $\mathrm{Zn}^{2+}$ ion interactions within the HqTp COF during the electrochemical charging and discharging process in a zinc ion unit cell; viz: (1) a pristine cathode (an electrode prior to any electrochemical perturbation/cycling); (2) a cathode at a fully discharged state (up to $0.2 \mathrm{~V} v$ s. $\mathrm{Zn} / \mathrm{Zn}^{2+}$; where $\mathrm{Zn}^{2+}$ do interact with $\mathbf{H q T p}$ ) and (3) fully charged up to $1.8 \mathrm{~V} v$ s. $\mathrm{Zn} / \mathrm{Zn}^{2+}$ (at this stage, $\mathrm{Zn}^{2+}$ are withdrawn from the HqTp cathode). Then, we have characterized the electrodes, followed by washing with water.

FT-IR spectroscopy of the pristine organic cathode is found to be similar to the pristine HqTp (Fig. 2a; ESI, Fig. S6b †). The $\mathrm{C}=\mathrm{O}$ group from $\beta$-ketoenamine framework appeared at $1584 \mathrm{~cm}^{-1}$. After charging up to $1.8 \mathrm{~V} v s . \mathrm{Zn} / \mathrm{Zn}^{2+}$, the hydroquinones are electrochemically oxidized to quinones. This has been confirmed by the observation of a new stretching vibrational peak formed at $1603.0 \mathrm{~cm}^{-1}$. When the system is discharged to $0.2 \mathrm{~V} v$ s. $\mathrm{Zn} / \mathrm{Zn}^{2+}$, a simultaneous diminishing of both $\mathrm{C}=\mathrm{O}$ groups is evident from the FT-IR spectra. Still, a diligent observation shows the presence of a very weak stretching peak at the $\mathrm{C}=\mathrm{O}$ region of the discharged cathode which indicates that the first cycle of discharging is not sufficient for the full utilization of the $\mathrm{C}=\mathrm{O}$ s in the framework. Additionally, to figure out the efficiency of the COF based organic cathode, we have strategically performed 500 chargedischarge cycles for a cell. After complete discharging up to $0.2 \mathrm{~V}$ vs. $\mathrm{Zn} / \mathrm{Zn}^{2+}$, the cathode was again subjected to FT-IR analysis (ESI, Fig. S6b $\dagger$ ). The full disappearance of the $\mathrm{C}=\mathrm{O}$ stretching peaks suggests the prospect of the effective utilization of active groups in HqTp for the interaction with $\mathrm{Zn}^{2+}$.

We have performed ${ }^{13} \mathrm{C}$ CP-MAS NMR spectroscopy of HqTp and discharged $\left(0.2 \mathrm{~V}\right.$ vs. $\left.\mathrm{Zn} / \mathrm{Zn}^{2+}\right)$ HqTp cathode to investigate for any chemical modifications at the atomic level of the framework (Fig. 2c; ESI, Fig. S7†). It showcases a down field chemical shift of the $\mathrm{C}=\mathrm{O}$ peak from $184.0 \mathrm{ppm}$ (for HqTp) to 190.0 ppm (for discharged HqTp). Similarly, the distinct 5$7 \mathrm{ppm}$ downfield chemical shifts have been observed for every peak of the discharged HqTp cathode compared to pristine HqTp COF (ESI, Fig. S7 and S8†). It could be due to the appearance of the deshielding effect because of intercalated electropositive $\mathrm{Zn}^{2+}$ ions, which decrease the electron density in the framework. ${ }^{9}$

The X-ray photoelectron spectroscopy (XPS) provides information about the chemical state of the concerned elements in the pristine, charged, and discharged conditions of HqTp. In the XPS profile of the discharged HqTp electrode $(0.2 \mathrm{~V} v s . \mathrm{Zn} /$ $\mathrm{Zn}^{2+}$ ), the sharp peaks are visible at the binding energy of 1022.0 and $1045.0 \mathrm{eV}$, which correspond to $\mathrm{Zn} 2 \mathrm{p}_{3 / 2}$ and $\mathrm{Zn} 2 \mathrm{p}_{1 / 2}$. Meanwhile, the intensity of the XPS peaks of $\mathrm{Zn}^{2+}$ in the charged electrode diminished by half concerning the discharged peak due to the removal of $\mathrm{Zn}^{2+}$ ions from the cathode (Fig. 2b; ESI, Fig. S17-S19†).

Moreover, the ex situ analysis is extended to electronic imaging techniques with elemental mapping. The TEM images 

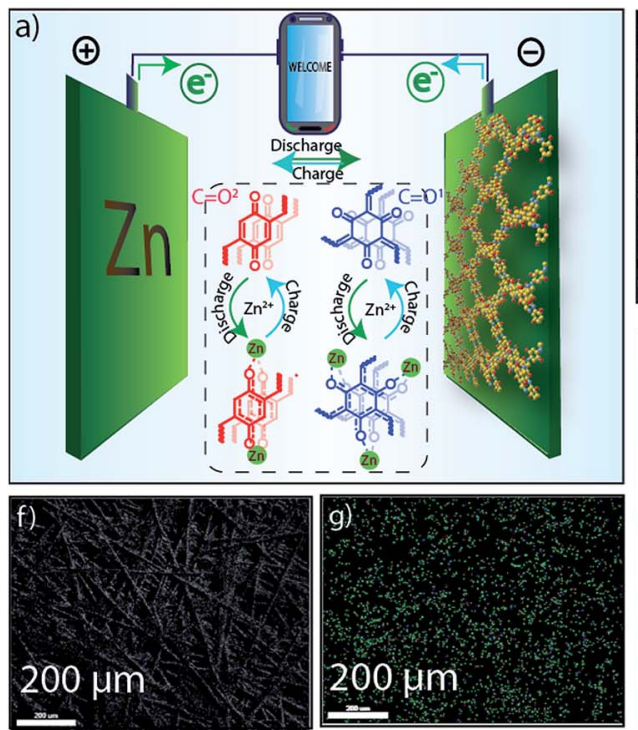
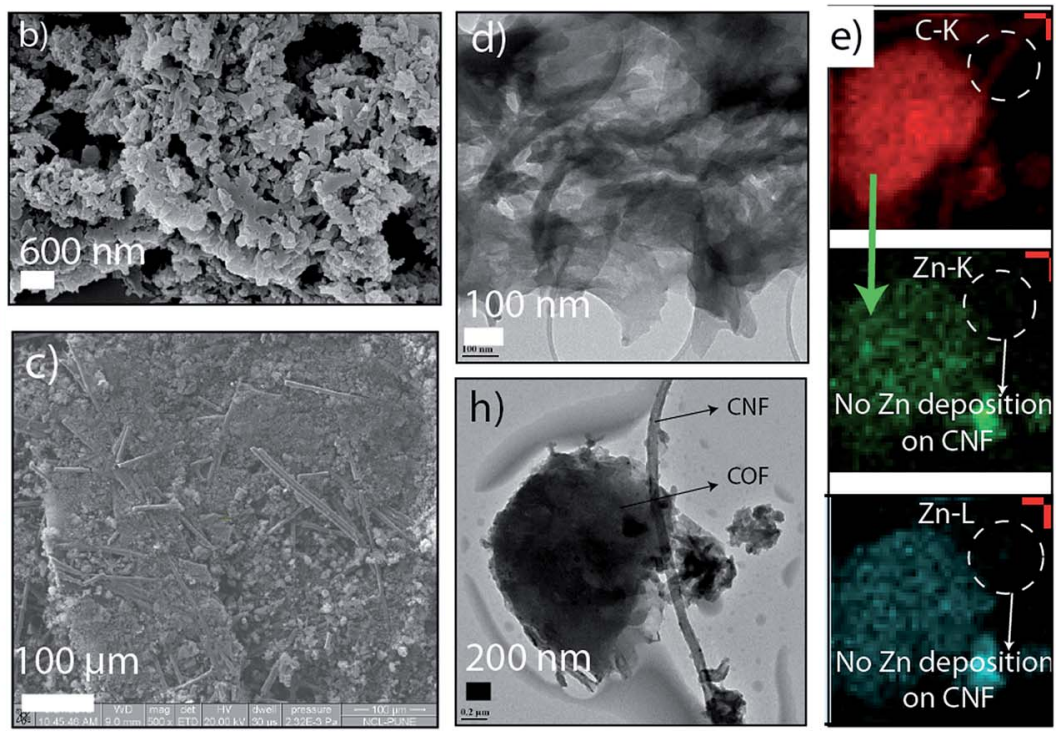

Fig. 3 (a) Diagrammatic representation of the aqueous Zn/HqTp unit cell. SEM image of the (b) HqTp; (c) the pristine HqTp organic cathode. (d) The TEM image of HqTp. (e) TEM elemental mapping images of carbon and zinc. (f) SEM elemental mapping of carbon (grey) and (g) zinc (green) of organic cathode discharged to $0.2 \mathrm{~V} v \mathrm{z}$. $\mathrm{Zn} / \mathrm{Zn}^{2+}$. (h) The TEM image of HqTp organic cathode at the discharged state. It shows the presence of COF as well as CNF present in the electrode (all the charging and discharge potential are represented vs. $\mathrm{Zn} / \mathrm{Zn}^{2+}$ reference)

revealed the layered ribbon-like morphology of HqTp organic cathode with the lateral dimension of $\sim 200 \mathrm{~nm}$ length and $\sim 50 \mathrm{~nm}$ width (Fig. $3 \mathrm{~d}$ and h; ESI, S12 and S13†). It also displayed the presence of carbon nanofiber (CNF) which has been used as an electrical conductivity amplifier in the cathode. The elemental mapping of carbon and zinc shows an efficient distribution of carbon (red color) both in COFs as well as CNF (Fig. 3e; ESI, Fig. S13†). However, the zinc distribution is solely present in COF (green color) and not in CNF. It indicates that the $\mathrm{Zn}^{2+}$ ions only interact with COF due to the specific functional moieties and, here, CNF is free from any interaction with $\mathrm{Zn}^{2+}$ ions. It also points out that the role of CNF is limited only for improving electrical conductivity.

Furthermore, to explore the morphological evolution of HqTp organic cathode; the discharged; charged and the pristine electrodes were subjected to the SEM analysis. Notably, in the pristine organic cathode, the COF samples are well distinguished as the previous sheet-like morphology of HqTp COF (Fig. 3b and c; ESI, Fig. S14 \& 15†). Also, we have recorded the elemental mapping of $\mathrm{C}, \mathrm{N}, \mathrm{O}$, and $\mathrm{Zn}$ in the discharged HqTp which suggests the uniform distribution of $\mathrm{Zn}^{2+}$ within the HqTp cathode (Fig. $3 \mathrm{f}$ and g; ESI, Fig. S15 $\dagger$ ). Moreover, the intactness of morphology even after 500 continuous chargedischarge cycles proves the good stability of the organic cathode without any leaching in harsh electrochemical conditions (ESI, Fig. S16†).

The reversible and efficient intermolecular interaction of HqTp $\cdots \mathrm{Zn}^{2+}$ has further allowed us to fabricate an aqueous rechargeable zinc ion battery (Zn/HqTP unit cell) (Fig. 4a). The electrochemical impedance spectroscopy (EIS) analysis of the fabricated cell at OCV condition has been provided in Fig. 4b. From the plot, an equivalent series resistance (ESR) value of 0.8 $\Omega$ and a charge transfer resistance value of $91 \Omega$ were obtained.
Exploiting the over-potential advantages evolved because the usage of the zinc-salt, there are reports on aqueous zinc-ion batteries operable between the potential window of 0.2 to $2.2 \mathrm{~V}$ vs. $\mathrm{Zn} / \mathrm{Zn}^{2+} .{ }^{4,10}$ Considering this, the cathode materials should be compatible within the stability window offered by the aqueous electrolyte., ${ }^{4,10}$ Moreover, it is highly desirable for the cathode material to exhibit its redox properties at high potentials $(\geq 0.6 \mathrm{~V}) v s . \mathrm{Zn} / \mathrm{Zn}^{2+}$ to position it for practical applications. However, herein, we have chosen the potential range of $0.2 \mathrm{~V}$ to $1.8 \mathrm{~V}$ vs. $\mathrm{Zn} / \mathrm{Zn}^{2+}$ to showcases the complete charge-storage features of HqTp COF.

From the cyclic voltammetry (CV)-profile obtained at the scan rate of $0.1 \mathrm{mV} \mathrm{sec}^{-1}$, a distinct pair of redox peaks has been observed (Fig. 4c; ESI, Fig. S20 $\dagger$ ). The prominent sharp redox peaks at $1.12 / 1.0 \mathrm{~V}$ vs. $\mathrm{Zn} / \mathrm{Zn}^{2+}$ correspond to the quinone oxidation and reduction (Onset potentials: $0.9 / 1.4 \mathrm{~V}$ vs. $\mathrm{Zn} /$ $\left.\mathrm{Zn}^{2+}\right)$. Also, an enhancement of the current gain has been observed at the higher CV scan rates of 0.5 and $1 \mathrm{mV} \mathrm{sec}^{-1}$ (Fig. S21†). To decipher the role of hydroquinone in the specific capacity of the COF, we have assembled a $\mathbf{Z n / H q T P}$ unit cell with a non-hydroquinone analog of HqTp, i.e., PaTp as an organic cathode (Zn/PaTp unit cell) (ESI, Fig. S30†). However, a significantly less current response was noted from the $\mathrm{CV}$, i.e., only $\mathbf{1 8 . 0} \%$ compared to the $\mathbf{Z n / H q T p}$ cell at the same scan rate (ESI, Fig. S23†). Such observation, in turn, signifies the $\mathrm{Zn}^{2+}$ receptor capability of the hydroquinone functionality in the host framework.

The galvanostatic charge-discharge (GCD) profile of the $\mathbf{Z n}$ / HqTP cell displays its charge-storage properties in the adopted potential window without a voltage plateau. Herein, the (GCD) analysis shows that the HqTp cathode presents a significantly high discharge capacity of $276.0 \mathrm{~mA} \mathrm{~h} \mathrm{~g}^{-1}$ at the current rate of $125.0 \mathrm{~mA} \mathrm{~g}^{-1}$ (Fig. 4d; ESI, Fig. S22†). Notably, many cathode 

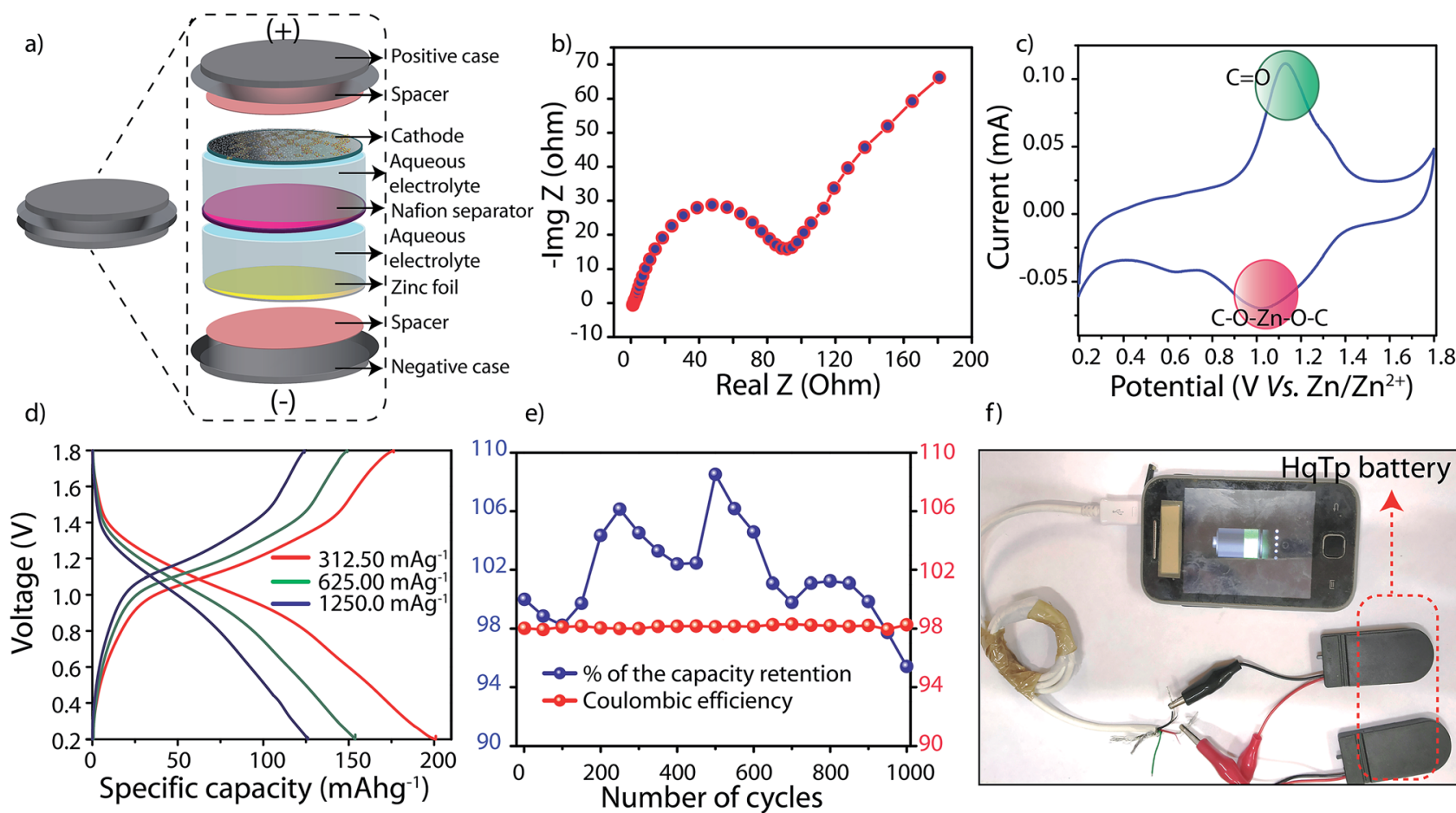

e)

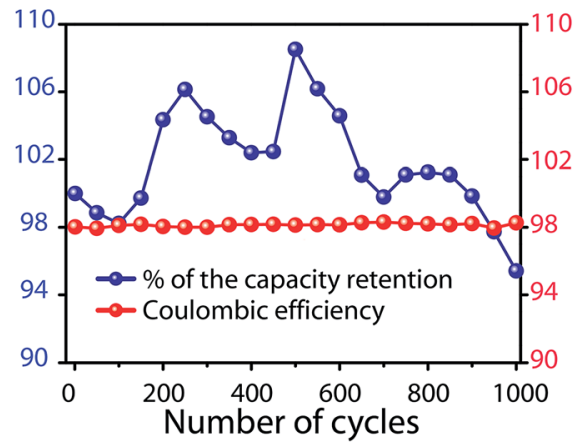

f)

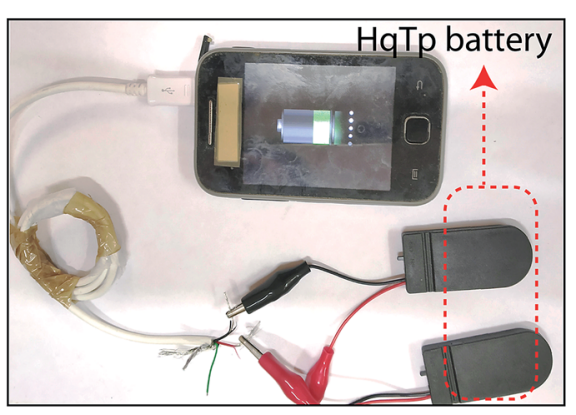

Fig. 4 (a) Diagrammatic representation of the fabrication of lab scale aqueous Zn/HqTP unit cell. Electrochemical characterizations of Zn/HqTP cell. (b) The impedance analysis of Zn/HqTP cell. (c) CV profile of Zn/HqTP cell. (d) Charge-discharge profile of Zn/HqTP cell. (e) Long-life cyclic stability and coulombic efficiency plot at $3750 \mathrm{~mA} \mathrm{~g}^{-1}$. (f) Digital photograph of charging a smart-phone by $\mathrm{Zn} / \mathrm{HqTP}$ cell.

materials have been explored for zinc-ion batteries showing charge-storage properties despite the absence of sharp voltage plateaus. ${ }^{11}$ Similarly, the same trend is observed for COF based $\mathrm{Li}$ or Na ion batteries as well. ${ }^{2 c, e}$ The lack of a voltage plateau of HqTp could be due to the polymeric porous nature of the material and it further indicates a hybrid charge-storage behavior. ${ }^{11}$ Moreover, it is worth mentioning that HqTp exhibits good performance in terms of the obtained discharge capacity as well as cyclic stability as an organic polymer cathode in aqueous zinc ion batteries (Table S4†)., ${ }^{3,12}$

Meanwhile, the PaTp COF exhibits only $121.0 \mathrm{~mA} \mathrm{~h} \mathrm{~g}^{-1}$ discharge capacity at the same current rate $\left(125 \mathrm{~mA} \mathrm{~g}^{-1}\right)$ (ESI, Fig. S24 $\dagger$ ). Considering the discharge capacity of $276.0 \mathrm{~mA} \mathrm{~h} \mathrm{~g}{ }^{-1}$, we have found that 7.5 number of $\mathrm{Zn}^{2+}$ ions interact in the unit cell of HqTp (ESI, S-9†). Moreover, at a current rate of $3750.0 \mathrm{~mA} \mathrm{~g}^{-1}$ where the organic cathode displays the specific capacity of $85.0 \mathrm{~mA} \mathrm{~h} \mathrm{~g}^{-1}$, we have carried out a long-term cyclic stability experiment of the HqTp zinc ion battery. The cyclic stability exceeded beyond 1000 cycles with 95\% retention of its initial capacity (Fig. 3d). Moreover, the coulombic efficiency of the cell is well maintained to $98 \%$ throughout the 1000 charge-discharge cycles (Fig. 4e). Although the symmetric shape of reversible peaks are absent in the $\mathrm{CV}$ profile, the coulombic efficiency over 1000 cycles indicate the high reversible charge storage characteristics of the HqTp COF. Besides, considering the average voltage of $0.87 \mathrm{~V}$ (Fig. S27†), a high energy density $\left(240.0 \mathrm{~W} \mathrm{~h} \mathrm{~kg}^{-1}\right)$ has been obtained at the power density of $109.0 \mathrm{~W} \mathrm{~kg}^{-1}$ as provided in the Ragone plot at the energy density of $75.0 \mathrm{~W} \mathrm{~h} \mathrm{~kg}^{-1}$, the power density increases to $3262.0 \mathrm{~W} \mathrm{~kg}^{-1}$ (ESI, Fig. S26†). We could assemble four $1.75 \mathrm{~V}$ HqTp-zinc ion cells in a series connection and directly used for charging a smart-phone device (Fig. 4f; ESI, Fig. S29†).

\section{Conclusions}

In summary, we have demonstrated hydroquinone stitched HqTp COF as a new class of organic cathode material for rechargeable aqueous zinc ion batteries. Herein, HqTp COF serves as a rich functional platform for binding $\mathrm{Zn}^{2+}$ ions. The efficient inter-layer interaction of these divalent $\mathrm{Zn}^{2+}$ ions with $\mathrm{C}=\mathrm{O}$ and $\mathrm{N}-\mathrm{H}$ from the adjacent layers provides an excellent discharge capacity $\left(276.0 \mathrm{~mA} \mathrm{~h} \mathrm{~g}^{-1}\right.$ at $\left.125.0 \mathrm{~mA} \mathrm{~g}^{-1}\right)$. We believe, the utility of $\mathrm{COF}$ as an organic cathode in such devices may lead to the further invention of more powerful crystalline polymer organic cathodes in the future.

\section{Conflicts of interest}

There are no conflicts to declare.

\section{Acknowledgements}

A. K. M, V. V, M. G., and A. H acknowledge UGC and CSIR for SRF. M. A. A. thanks the Materials Chemistry Consortium for computational resources on THOMAS (EP/P020194). S. K. acknowledges CSIR for funding through the project TLP003526. R. B. acknowledges IISER-Kolkata start-up research and DST- Swarnajayanti Fellowship grant for funding. 


\section{Notes and references}

1 (a) A. P. Cote, A. I. Benin, N. W. Ockwig, A. J. Matzger, M. O'Keeffe and O. M. Yaghi, Science, 2005, 310, 11661170; (b) P. Kuhn, M. Antonietti and A. Thomas, Angew. Chem., Int. Ed., 2008, 47, 3450-3453; (c) S.-Y. Ding and W. Wang, Chem. Soc. Rev., 2013, 42, 548-568; (d) S. Wang, Q. Wang, P. Shao, Y. Han, X. Gao, L. Ma, S. Yuan, X. Ma, J. Zhou, X. Feng and B. Wang, J. Am. Chem. Soc., 2017, 139, 4258-4261; (e) J. W. Crowe, L. A. Baldwin and P. L. McGrier, J. Am. Chem. Soc., 2016, 138, 10120-10123; (f) A. Sun, B. Aguila, J. Perman, N. Nguyen and S. Ma, J. Am. Chem. Soc., 2016, 138, 15790-15796; $(g)$ X. Han, Q. Xia, J. Huang, Y. Liu, C. Tan and Y. Cui, J. Am. Chem. Soc., 2017, 139, 8693-8697; (h) X.-H. Liu, C.-Z. Guan, S.-Y. Ding, W. Wang, H.-J. Yan, D. Wang and L.-J. Wan, J. Am. Chem. Soc., 2013, 135, 10470-10474; (i) M. Dogru, A. Sonnauer, A. Gavryushin, P. Knochel and T. Bein, Chem. Commun., 2011, 47, 1707-1709; (j) L. Stegbauer, K. Schwinghammer and B. V. Lotsch, Chem. Sci., 2014, 5, 2789-2793; (k) E. Q. Jin, M. Asada, Q. Xu, S. Dalapati, M. A. Addicoat, M. A. Brady, H. Xu, T. Nakamura, T. Heine, Q. H. Chen and D. L. Jiang, Science, 2017, 357, 673-676.

2 (a) J. Zhou and B. Wang, Chem. Soc. Rev., 2017, 46, 69276945; (b) C. R. DeBlase, K. E. Silberstein, T. T. Truong, H. D. Abruna and W. R. Dichtel, J. Am. Chem. Soc., 2013, 135, 16821-16824; (c) S. Wang, Q. Wang, P. Shao, Y. Han, X. Gao, L. Ma, S. Yuan, X. Ma, J. Zhou, X. Feng and B. Wang, J. Am. Chem. Soc., 2017, 139, 4258-4261; (d) M. -S. Kim, W.-J. Lee, S.-M. Paek and J. K. Park, ACS Appl. Mater. Interfaces, 2018, 10, 32102-32111; (e) S. Gu, S. Wu, L. Cao, M. Li, N. Qin, J. Zhu, Z. Wang, Y. Li, Z. Li, J. Chen and Z. Lu, J. Am. Chem. Soc., 2019, 141(24), 9623-9628.

3 (a) G. Fang, J. Zhou, A. Pan and S. Liang, ACS Energy Lett., 2018, 3, 2480-2501; (b) D. Kundu, B. D. Adams, V. Duffort, S. H. Vajargah and L. F. Nazar, Nat. Energy, 2016, 1, 16119; (c) A. Konarov, N. Voronina, J. H. Jo, Z. Bakenov, Y.-K. Sun and S.-T. Myung, ACS Energy Lett., 2018, 3, 2620-2640; (d) M. Ghosh, V. Vijayakumar and S. Kurungot, Energy Technol., 2019, 1900442.

4 (a) Q. Zhao, W. Huang, Z. Luo, L. Liu, Y. Lu, Y. Li, L. Li, J. Hu, H. Ma and J. Chen, Sci. Adv., 2018, 4, eaao1761; (b) Z. Guo, Y. Ma, X. Dong, J. Huang, Y. Wang and Y. Xia, Angew. Chem., Int. Ed., 2018, 57, 11737-11741; (c) D. Kundu, P. Oberholzer, C. Glaros, A. Bouzid, E. Tervoort, A. Pasquarello and M. Niederberger, Chem. Mater., 2018,
30, 3874-3881; (d) F. Wan, L. Zhang, X. Wang, S. Bi, Z. Niu and J. Chen, Adv. Funct. Mater., 2018, 1804975; (e) L. Ma, S. Chen, H. Li, Z. Ruan, Z. Tang, Z. Liu, Z. Wang, Y. Huang, Z. Pei, J. A. Zapien and C. Zhi, Energy Environ. Sci., 2018, 11, 2521-2530.

5 (a) S. Kandambeth, A. Mallick, B. Lukose, M. V. Mane, T. Heine and R. Banerjee, J. Am. Chem. Soc., 2012, 134, 19524; (b) S. Chandra, D. R. Chowdhury, M. Addicoat, T. Heine, A. Paul and R. Banerjee, Chem. Mater., 2017, 29, 2074-2080.

6 (a) K. M. Engle, T.-S. Mei, M. Wasa and J.-Q. Yu, Acc. Chem. Res., 2012, 45, 788-802; (b) S. D. Sarkar, W. Liu, S. I. Kozhushkov and L. Ackermann, Adv. Synth. Catal., 2014, 356, 1461-1479.

7 (a) A. Haaland, Angew. Chem., Int. Ed., 1989, 28, 992-1007; (b) M. Yamakawa and R. Noyori, Organometallics, 1999, 18, 128133.

8 (a) E. W. L. Chan and M. N. Yousaf, J. Am. Chem. Soc., 2006, 128, 15542-15546; (b) C. Nicosia and J. Huskens, Mater. Horiz., 2014, 1, 32-45.

9 (a) J. C. Hammel and J. A. S. Smith, J. Chem. Soc. A, 1969, 2883-2887; (b) C. A. Wilkie and D. T. Harworth, J. Inorg. Nucl. Chem., 1978, 40, 195-197.

10 (a) M. H. Lee, S. J. Kim, D. Chang, J. Kim, S. Moon, K. Oh, K.-Y. Park, W. M. Seong, H. Park, G. Kwon, B. Lee and K. Kang, Mater. Today, 2019, DOI: 10.1016/ j.mattod.2019.02.004; (b) L. Suo, O. Borodin, T. Gao, M. Olguin, J. Ho, X. Fan, C. Luo, C. Wang and K. Xu, Science, 2015, 350, 938-943.

11 (a) H. Pan, Y. Shao, P. Yan, Y. Cheng, K. S. Han, Z. Nie, C. Wang, J. Yang, X. Li, P. Bhattacharya, K. T. Mueller and J. Liu, Nat. Energy, 2016, 1, 16039; (b) D. Kundu, B. D. Adams, V. Duffort, S. H. Vajargah and L. F. Nazar, Nat. Energy, 2016, 1, 16119-16126; (c) S. Chen, L. Ma, K. Zhang, M. Kamruzzaman, C. Zhia and J. A. Zapien, J. Mater. Chem. A, 2019, 7, 7784-7790; (d) C. Xia, J. Guo, Y. Lei, H. Liang, C. Zhao and H. N. Alshareef, Adv. Mater., 2018, 30, 1705580; (e) Z. Luo, L. Liu, J. Ning, K. Lei, Y. Lu, F. Li and J. Chen, Angew. Chem., Int. Ed., 2018, 57, 94439446; (f) S. Wang, Q. Wang, P. Shao, Y. Han, X. Gao, L. Ma, S. Yuan, X. Ma, J. Zhou, X. Feng and B. Wang, J. Am. Chem. Soc., 2017, 139(12), 4258-4261.

12 (a) H. Karami, M. F. Mousavi and M. Shamsipur, J. Power Sources, 2003, 117, 255-259; (b) H.-Y. Shi, Y.-J. Ye, K. Liu, Y. Song and X. Sun, Angew. Chem., Int. Ed., 2018, 57, 16359-16363. 